\title{
MATERIALISMO HISTÓRICO-DIALÉTICO E A PESQUISA EM EDUCAÇÃO AMBIENTAL
}

\author{
Carlos Frederico B. Loureiro ${ }^{1}$
}

Resumo: Neste artigo trago algumas das reflexões expostas na palestra proferida no VII Encontro de Pesquisa em Educação Ambiental, realizado na UNESP de Rio Claro em 2013. Para fins de delimitação, apresento aspectos polêmicos do materialismo histórico-dialético e, principalmente, conceitos que ajudam a entender a ontologia do ser social aí contida, por sua relevância na compreensão do metabolismo sociedade-natureza e do debate ambiental. Ao destacar categorias fundamentais da tradição iniciada em Karl Marx, argumento a favor da pertinência e atualidade desta para uma perspectiva crítico-transformadora da educação ambiental.

Palavras-chave: Materialismo histórico-dialético. Pesquisa. Educação ambiental.

\section{HISTORICAL-DIALECTICAL MATERIALISM: CONTRIBUTIONS TO RESEARCH ON ENVIRONMENTAL EDUCATION}

Abstract: This article presents some of the reflections expressed in the lecture given at the VII Environmental Education Research Meeting, held at UNESP, Rio Claro, in 2013. For the purpose of delimitation, controversial aspects of historicaldialectical materialism and, mainly, concepts that help understand the ontology of the social being there included-due to its relevance in understanding the metabolism society-nature and environmental debate-are discussed. While highlighting the fundamental categories of the tradition initiated in Karl Marx, this article argues in favor of its relevance for a critical and transforming perspective of environmental education.

Keywords: Historical-dialectical materialism. Research. Environmental education.

\section{MATERIALISMO HISTÓRICO Y DIALÉTICO Y LA INVESTIGACIÓN EN EDUCACIÓN AMBIENTAL}

Resumen: En este artículo traigo algunas de las reflexiones que se presentaron en el VII Encuentro de Investigación sobre Educación Ambiental, realizado en la UNESP, Rio Claro/SP, en 2013. A los efectos de delimitación, presento aspectos controvertidos del materialismo histórico y dialéctico, y especialmente, los conceptos que ayudan a comprender la ontología del ser social que ahí se contiene, por su relevancia en la comprensión del metabolismo entre la sociedad y la naturaleza y el debate ambiental. Al poner de relieve las principales categorías de la tradición iniciada en Karl Marx, sostengo la relevancia y

\footnotetext{
1 Professor dos programas de pós-graduação em educação e em psicossociologia de comunidades e ecologia social - UFRJ. Colaborador do programa de pós-graduação em educação ambiental - FURG. Coordenador do Laboratório de Investigações em Educação, Ambiente e Sociedade - LIEAS/UFRJ. Pesquisador CNPq. floureiro@openlink.com.br
} 
actualidad de las mismas por una perspectiva crítica y transformadora de la educación ambiental.

Palabras clave: Materialismo histórico y dialéctico. Investigación. Educación ambiental.

\section{Introdução}

Neste artigo resgato alguns dos aspectos abordados na palestra proferida no dia 9 de julho de 2013, durante o VII Encontro de Pesquisa em Educação Ambiental (EPEA), realizado na UNESP de Rio Claro. Longe de querer esgotar temática das mais estudadas e debatidas entre intelectuais, militantes de movimentos sociais e de partidos políticos de todos os continentes desde final do século XIX, busco recuperar a pertinência da tradição marxista, particularmente do seu método de investigação científica, o denominado materialismo histórico-dialético. Em relação a este, por sua natureza ontológica, epistêmica e política, procuro explicitar algumas de suas categorias determinantes, elucidando pontos pouco conhecidos ou compreendidos na educação ambiental. Como o espaço de um artigo é reduzido, para cada assunto tratado, os argumentos são acompanhados de significativo número de indicações bibliográficas para que o leitor possa buscar aprofundamento em momento posterior à leitura do texto.

Entendo que o convite para fazer a palestra no VII EPEA decorreu do aumento expressivo de publicações e pesquisas que se utilizam, direta ou indiretamente, de categorias marxistas, não só na educação ambiental, mas por quem atua no campo ambiental, das ciências, da filosofia e da política. Declarado morto, inúmeras vezes, nos últimos 100 anos, o materialismo histórico-dialético se renova, fato patente na proliferação de pesquisas feitas com base neste, na retomada de espaços fecundos entre intelectuais e militantes (EAGLETON, 2012; HARVEY, 2013 e 2005), no interesse que eventos marxistas têm despertado e na proliferação de novas edições de livros clássicos e recentes de autores marxistas em diversos países.

Considero que esse interesse renovado não é casual, mas manifesta a busca de pesquisadores, intelectuais e militantes por referenciais teóricos e metodológicos que nos auxiliem em um momento de enorme turbulência política, incertezas quanto ao futuro da vida planetária, intensificação do uso material sem redução significativa da fome e da pobreza e acirramento dos conflitos em torno do uso e apropriação da natureza (ZIEGLER, 2013). Tal cenário tem possibilitado novas indagações acerca das relações sociais estabelecidas, da forma de organização social hegemonizada e dos caminhos para a superação do atual processo de produção destrutiva e mercantilização da vida (MÉSZÁROS, 2004, 2002), que caracterizam a sociedade capitalista (HARVEY, 2011; WALLERSTEIN, 2001).

A fase contemporânea do capitalismo, ao mesmo tempo em que espetaculariza a vida social $^{2}$ (DEBORD, 1997), privatiza a dimensão pública, esvazia a ação política no Estado e vincula a condição de cidadania ao padrão de consumo, afetando a

\footnotetext{
2 Para Debord (1997), no que denominou por Sociedade do Espetáculo, na atual fase do capitalismo, a mercadoria ocupa quase que totalmente a vida social. A origem da espetacularização é a perda da unidade do mundo, do diverso, que se submete à desigualdade que fragmenta e antagoniza as relações sociais. A sua linguagem diz reunir os separados, mas os reúne como separados que se relacionam pela dominação e pela ideologia utilitária do mercado.
} 
possibilidade material de sobrevivência das pessoas e colocando sob risco de extinção inúmeras outras espécies. Cria, assim, uma sensação de maior autonomia individual e de criação cultural, em uma apologética idealizada do plural, contudo, sob crescente concentração de poder político e acúmulo econômico (JAMESON, 1996).

O fetiche da mercadoria (MARX, 2006, BENSAÏD, 1999) se estabeleceu em escala planetária, sob um modelo de desenvolvimento que prima pelo acelerado uso do que a natureza dispõe para a perpetuação da vida, viabilizando a compressão do ciclo produção-circulação-distribuição-consumo e garantindo a ampliação da acumulação privada da riqueza socialmente gerada (CASANOVA, 2006; HARVEY, 2013a). Tal complexo de relações estruturais do capitalismo estabelece uma impressionante teia de interdependência econômica e política global, com efeitos diretos sobre a livre manifestação e respeito à diversidade cultural e outras formas de produzir e garantir a reprodução material da vida (ALTVATER, 2010; LOUREIRO, 2012). Mais do que em quaisquer períodos anteriores, estamos diante de uma formação social que se mundializa (CHESNAIS, 1996) e passa a afetar, em maior ou menor medida, todas as demais possibilidades alternativas de vida social que foram objetivadas ou sonhadas nos últimos três séculos. "Assim, na sociedade dominada pelo capital, a liberdade e a igualdade passam a ter como alicerces escravidão e desigualdade" (SALLUM JR, 2005, p.36).

Assim, permeando as reflexões e formulações que se seguem, parto do pressuposto que a tradição inaugurada por Marx tem uma contribuição que não pode ser desprezada (BORON, 2006), sendo necessária para os que buscam alternativas ecologicamente viáveis e socialmente justas (CASANOVA, 2004). Sustento tal posição por alguns motivos:

- Porque o materialismo histórico-dialético se mostra vigoroso na compreensão das relações sociais de homens e mulheres com a natureza e das mediações que caracterizam as ações dos indivíduos sociais no mundo (ALTVATER, 2006). O que contribui sobremaneira para o entendimento de que as relações com a natureza, enquanto identidade e pertencimento à totalidade complexa da vida, e as relações de apropriação da natureza, enquanto utilização econômica, são históricas e relativas às relações sociais e modos de produção (formações sociais) e não condições atemporais ou estritamente pessoais (LOUREIRO, 2011; MÉSZÁROS, 2006).

- Em função da capacidade que esse método tem de explicar processos que definem as diferentes formas de uso e apropriação da natureza, produção material e organização cultural na história, ou seja, como agentes sociais concretos, sob condições determinadas, criam suas formas de existência social.

- Porque o método dialético permite uma leitura não-fatorialista e nãodicotomizada de temas atuais de enorme relevância (classe, gênero, direitos humanos, conflitos étnico-raciais etc.), sabendo relacionar constitutivamente igualdade e diversidade ${ }^{3}$ nas lutas sociais (KONDER, 1992, 1997; KOSIK, 1976; HAUG, 2006; VÁZQUEZ, 2011).

\footnotetext{
3 “Que significa então tratar duas pessoas por igual? Sem dúvida, não significa trata-las da mesma maneira, visto que, se esses indivíduos possuem necessidades e capacidades distintas, o tratamento idêntico acabaria por resultar em injustiça. Foi por esse motivo que Marx, em seu A crítica ao Programa de Gotha e alhures, reputou a noção de igualdade como uma típica abstração burguesa, que se modelou furtivamente na troca de mercadorias. [...] Tratar duas pessoas de modo igual deve na verdade significar não dar a elas exatamente o mesmo tratamento, mas cuidar de modo igual de suas diferentes
} 
- Porque, naquilo que se refere diretamente à questão ambiental, a natureza em Marx é realisticamente prioritária sobre a sociedade, uma unidade auto-organizada de diferentes níveis em uma totalidade complexa. Por sua visão filosoficamente tida como materialista ${ }^{4}$, há o pressuposto de que somos natureza, de que esta antecede à existência humana e existe para além desta. Portanto, em Marx, dada a centralidade do aspecto ontológico, é invariável, na história, o fato de que a reprodução e produção da sociedade dependem da natureza (FOSTER, 2005) ${ }^{5}$.

- Porque a inclusão simplificada de Marx entre os modernos em contraponto aos pós-modernos, configurados como dois blocos monolíticos em que o segundo representa o que há de atual e uma superação linear do primeiro, justificando sua condenação à lata de lixo da história, é de extrema fragilidade argumentativa ${ }^{6}$. Primeiro, porque tal divisão, sem considerar as especificidades sócio-históricas e a

necessidades. Elas não são indivíduos iguais, e sim igualmente indivíduos. E nesse sentido um conceito sensato de igualdade já implica a noção de diferença." (EAGLETON, 1998, p. 114).

${ }^{4} \mathrm{O}$ conceito de material em Marx é distinto de como o senso comum normalmente entende (apego a bens materiais e crença de que as coisas se esgotam nos processos físicos). Como esse é um longo tema de debate na filosofia, que não interessa aqui, lembro apenas que Marx não reduz o que é material ao ente com massa e energia. Associa a dinâmica material à própria relação, à produção pelo trabalho e à práxis (LESSA, 2003; KOFLER, 2010). Como bem coloca Mota (2005, p. 2), "Como disse o próprio Marx, "materialismo abstrato" e "espiritualismo abstrato" tocam-se, e não se trata de escolher um ou outro, mas "a verdade que une os dois" para aquém da sua separação". A determinação ser material significa tão somente que são as condições objetivas/objetivadas que estabelecem os pontos iniciais de nosso movimento ativo no mundo (MARX; ENGELS, 2002). Ver também boa análise deste tema em Bensaïd (1999), Sampaio e Frederico (2006) e Labica (1990).

5 Não obstante a crítica a Marx de que ele desconsiderou, no grau de importância que mereceria, a discussão dos fluxos energéticos e a Lei da Entropia, deixando de dar um peso adequado aos limites ecossistêmicos impostos à nossa condição biológica-social, é impreciso dizer que ele a desprezava ou que não admitia a importância dessas variáveis na teoria do valor. Na verdade, Sergei Podolinsky, socialista ucraniano, considerado um dos pioneiros da chamada economia ecológica, submeteu suas considerações a Marx, na década de 1880, não obtendo resposta direta do mesmo. De qualquer forma, duas questões devem ser lembradas. Engels respondeu a Podolinsky e considerou relevantes suas formulações, contudo, chamou a atenção para não se dissociar dos processos energéticos as relações sociais e o modo de produção que definem as mediações com a natureza pelo trabalho (o que não significa desconsiderar a entropia, mas, sim, enfatizar as mediações). Além disso, Marx foi um leitor atento de autores das ciências classificadas como naturais, dentre eles, com enorme atenção, Darwin, Haeckel (para muitos, o criador do conceito de ecologia) e Liebig, autor no qual se inspira para discutir a problemática cidade-campo e para formular seu importante conceito de metabolismo sociedade-natureza, principalmente em sua forma negativa: a falha metabólica que o capital impõe ao estabelecer ciclos produtivos que rompem com o equilíbrio dinâmico da natureza, conceito este central na leitura e entendimento de $O$ Capital, principalmente os volumes 1 e 3 (MARX, 2006).

${ }^{6}$ É oportuno recordar que é superficial afirmar que hoje existem questões que não existiam no século XIX, o que justificaria o abandono do método e da teoria marxiana em nome de orientações teóricas mais recentes. A discussão, efetivamente, não é esta, e sim, se o método comporta e prevê a dinâmica das condições concretas historicamente delineadas em suas contradições ou não. $\mathrm{O}$ abandono do pensamento crítico não é uma questão de atualização, mas de troca de posições epistemológicas com sérias implicações práticas e políticas. Como bem coloca Saviani (2004), as discussões presentes na atual filosofia do indivíduo ou na ideia de morte do sujeito são de meados do século XIX, algo que se encontra, por exemplo, em uma longa exposição de Marx criticando tais posições, manifestas em Max Stirner, já em A ideologia alemã (MARX; ENGELS, 2002). Outro exemplo ilustrativo pode ser observado nos textos de Horkheimer do início da década de 1920 (HORKHEIMER, 1990), em sua crítica ao sentido de verdade no pragmatismo (posicionamento filosófico amplamente aceito na contemporaneidade), reafirmando a validade de tal conceito no âmbito da teoria marxista. Logo, a discussão não é a estéril oposição entre o que é novo e o que é velho, mas está na disputa prática e política entre concepções de mundo e de sociedade. 
dinâmica contraditória do pensamento ocidental, pouco ajuda em termos heurísticos. Segundo, porque Marx, assim como Nietzsche, entre outros, trouxe críticas agudas ao pensamento de sua época, o que torna injusta a inserção de ambos em um pacote fechado, compartilhando das mesmas crenças relativas ao progresso, à história e à condição humana no planeta que nomes como Kant, Locke, Rousseau, Hegel etc. (que caracterizaram o pensamento moderno hegemonizado - liberal e burguês).

Essa atualidade é antes de tudo a da universalização e da vitalidade mórbida do próprio capital. Tornando-se efetivamente planetário, ele é mais do que nunca o espírito de nossa época sem espírito e o poder impessoal do reino da mercadoria. Nosso nublado horizonte e nosso triste quinhão. Enquanto o capital continuar dominando as relações sociais, a teoria de Marx permanecerá atual, e sua novidade sempre recomeçada constituirá o reverso e a negação de um fetichismo mercantil universal. "Escrevendo em preto-e-branco algo vermelho", O Capital pôs em crise "a humanidade européia". Longe de abafar esse "trovão inaudível", as conturbações aceleradas do mundo permitem enfim que ele seja ouvido (BENSAÏD, 1999, p.11-12).

Já ouvi educadores ambientais argumentarem que não utilizam o materialismo histórico-dialético porque este modo de pensar e fazer, bem como a tradiçção marxista como um todo, não contempla a questão ambiental. Há pelo menos duas imprecisões nessa afirmação. Uma de natureza ontológica e epistemológica, que explicarei adiante, e outra de desconhecimento histórico. É preciso recordar, sem tornar a lista extensa, de nomes com forte significado na história do marxismo, como: Rosa Luxemburgo (que evidenciou enorme preocupação e sensibilidade ecológica e amor pela natureza); Cristopher Caudwell, William Morris (um dos pais do ambientalismo britânico e inspirador da historiografia marxista inglesa); Ernest Bloch (que manifestou profunda discordância à fé que a ortodoxia oficial marxista tinha em relação ao progresso); Theodor Adorno (que afirmou ser a natureza a categoria central de Marx e o limite ao capital); Walter Benjamin (que negou o determinismo histórico e afirmou ser um projeto imperialista a dominação da natureza); Herbert Marcuse (que repensou os sujeitos históricos do processo revolucionário e criticou vigorosamente a alienação que o capitalismo produz - denominando tal processo de imbecilização da humanidade); e Eric Fromm (que manifestou sua preocupação quanto à possibilidade de sobrevivência de nossa espécie diante da barbárie do capitalismo). Em sua apropriação do sul, podemos recordar das originais formulações de José Carlos Mariátegui, Amílcar Cabral, Ernesto Che Guevara, Eduardo Galeano e Chico Mendes ${ }^{7}$.

Caso houvesse incompatibilidade epistemológica entre a dialética materialista histórica e a ecologia, como explicar que dois dos maiores ecólogos do século XX, Vavilov e Vernadsky, tenham se pautado em tal método para suas formulações, sendo o segundo, inclusive, citado por Lynn Margulis como a primeira pessoa na história a pensar as implicações concretas das interdependências da natureza? Ou ainda, como justificar a importância do materialismo dialético, na obra de nomes de influentes

\footnotetext{
${ }^{7}$ Como não é possível avançar na contribuição destes últimos, é oportuna a leitura de: Dussel (2012), Mariátegui (2005), Löwy (2005, 2006).
} 
cientistas naturais como Stephen J. Gould (paleontólogo, historiador natural), R. Levins (ecólogo), R. Lewontin (geneticista)?

Como bem coloca Foster (2005), as explicações para a presença original da natureza como categoria ontologicamente determinante, no final do século XIX e início do século XX, e seu desaparecimento durante boa parte do século XX (entre as décadas de vinte e de setenta, destacadamente), decorreram de omissões ou elementos insuficientes em Marx, e fundamentalmente de aspectos políticos que geraram situações em que tal discussão foi apagada pelos diversos ismos. E isto se deu até chegarmos às gerações mais recentes de marxistas, que passam a colocar no debate ambiental considerável centralidade para a superação do capitalismo (FOSTER, 1999, 2002; O’Connor, 2003) ${ }^{8}$.

Não dialogar com a tradição crítica a partir desse olhar historicizado, considerando suas imprecisões e ausências, na riqueza da própria formulação crítica, bem como seus usos para atendimento de finalidades ideopolíticas, acabou por levar a uma compreensão de tal tradição de modo congelado. Isso gera ou uma recusa em bloco ou uma tentativa de classificação formalista que, por vezes, leva a se procurar, estranhamente, retirar do interior do pensamento marxista aquilo que foi absolutamente decisivo para o próprio pensamento de Marx ${ }^{9}$. Logo, se é possível sustentar que há mais do que simpatia ou afinidade moral por ideais de esquerda, o que há no materialismo histórico-dialético que garanta a discussão ambiental no pensamento crítico?

\section{A ontologia do ser social: fundamento para entender o metabolismo sociedade- natureza}

Em acordo com a extensa revisão histórica, ontológica e epistemológica feita por Foster (2005), a concepção de natureza presente em Marx não atende a nenhuma forma de determinismo da coisalidade material sobre o espírito ou vice-versa, mas expressa a noção de totalidade auto-organizada que, em seu movimento, estabelece suas próprias leis de realização. Chauí (2006) lembra que tal concepção implica afirmar que a materialidade dos processos que contam com a atividade humana não pode ser vista de modo mecânico e linear, pois nas próprias relações causais se inserem as ações dos agentes sociais. A determinação material, portanto, deve ser entendida como momentos e condições objetivas e objetivadas das quais partimos em nosso movimento de transformação e constituição do ser social (CHASIN, 2009) e da própria realidade em movimentos complexos e contraditórios.

A natureza, devindo na história por meio do ato da produção da sociedade, é a própria natureza humana, que se constitui na dinâmica da natureza, pressuposto da atividade humana. Desse modo, conforme recorda Duarte (1995), já nos Manuscritos de 1844 e mais claramente a partir das Teses sobre Feuerbach e A ideologia alemã, para

\footnotetext{
8 Parte dessa produção internacional pode ser encontrada em periódicos de ecologia política, principalmente na Itália, Espanha, Inglaterra, México, Argentina, entre outros, e na conhecida revista norte-americana Capitalism, Nature, Socialism.

${ }^{9}$ Um exemplo notável disso é observado em Hannah Arendt. Uma indiscutível defensora da democracia e da liberdade, pensadora e ativista política de rara genialidade. Esta entendeu a tradição marxista sob o prisma da ortodoxia e, ao não desenvolver satisfatoriamente sua compreensão acerca dos conceitos de práxis, trabalho e dialética, acabou definindo Rosa Luxemburgo, pessoa por ela admirada e de referência, como não marxista (STORLOKEN, 2006). Este tipo de equívoco deveu-se, exatamente, ao fato de a mesma ter criado uma classificação formal na qual Rosa não se encaixava, devendo, portanto, estar fora, o que é muito pouco razoável de ser sustentado.
} 
Marx não existem duas essências: a humana e a natural, mas, sim a dialética natureza histórica-história natural, a unidade da natureza que está para além de nós e a partir da qual nos realizamos e a significamos por mediações várias, no perpétuo movimento de criação (PORTO-GONÇALVES, 1989).

Em termos práticos, esta concepção de natureza significa evitar a comum oposição entre natureza e cultura nas discussões relativas à proteção e conservação ambiental, pois historiciza os processos e evidencia que os problemas existentes decorrem de formas específicas de organização da vida social e não de uma inerente tendência humana a querer destruir o planeta ou de uma dualidade de essências (a natural e a humana) (MARX; ENGELS, 2002; NETTO, 2012).

Isto, contudo, significa que para Marx, mesmo não havendo um fim inexorável, há intencionalidade e projeção na ação dos agentes sociais e a possibilidade de identificação de tendências em função da apreensão das próprias contradições nas relações geradas. Nesse sentido, toda ação humana é teleológica, mas não a história. Ou seja, a história não está pré-definida ou caminha de modo inexorável para o progresso. A história é aberta, e nesta há ação política, práxis, que nos permite agir intencionalmente na construção de outra sociedade, permitindo afirmar a utopia da emancipação $^{10}$ como possibilidade a ser buscada por meio do enfrentamento e explicitação dos conflitos sociais instaurados na dinâmica societária capitalista (BORNHEIM, 1977).

Marx, em resumo, trouxe elementos para a constituição de um método capaz de analisar o movimento de vir a ser da natureza, mais precisamente uma dialética social na natureza ${ }^{11}$, movimento este objetivado por meio da práxis (com destaque ontológico à práxis produtiva - o trabalho, enquanto mediação metabólica da relação sociedadenatureza), num processo de estar no mundo, de agir no mundo, de ser o/no mundo, transformando-se e transformando-o (MÉSZÁROS, 2013).

Conforme nos ensina Lukács (2010, 2012), o momento de produção de meios de vida e satisfação de necessidades é indissociável e condição para a sociabilidade, a

\footnotetext{
${ }^{10}$ Não raramente entre ambientalistas brasileiros se afirma que o pensamento marxista é parcial, no que se refere à emancipação, pois a busca apenas para a classe trabalhadora. Este é um erro de entendimento, pois o que se busca é a emancipação humana como um todo, contudo, tendo clareza de que esta não ocorrerá sem a superação dos processos econômicos e político-institucionais de expropriação, vinculados aos processos ideológicos de legitimação dos preconceitos e outras formas de dominação. Assim, a emancipação na tradição marxista deixa de ser um discurso associado aos indivíduos e a uma humanidade abstrata e se articula ao complexo relacional indivíduos-grupos-classes, definidor e definido pelas condições estruturais do capitalismo. Na dialética, a superação de algo pressupõe a ação dos que são os portadores materiais de sua negação, visando sua própria dissolução, pela supressão das relações existentes. Logo, o protagonismo do proletariado e demais grupos expropriados não visa apenas sua própria libertação, mas a mudança objetiva do conjunto de relações sociais.

${ }^{11}$ Esse é um ponto polêmico não amarrado em Marx, que não explicitou se entendia que a dialética era própria da natureza em sua totalidade ou apenas dos fenômenos historicossociais na natureza. Deixa entender, principalmente nos Manuscritos de 1844, em A sagrada família e nos Grundrisse que a dialética é da natureza (o que o aproxima de algumas teorias da complexidade). Posição esta que é enfaticamente sustentado por Engels (1986, 1986a), não sem problemas conceituais que desembocam em evolucionismos deterministas (BENOIT, 2000). Este debate foi intenso no campo marxista, particularmente entre Adorno e Lukács (TERTULIAN, 2007) e na França na década de 1960. Um dos eventos emblemáticos, que sinalizam para a intensidade dos debates naquele país, ocorreu diante de um público superior a seis mil estudantes. Neste, Sartre (marxista-existencialista) e Hyppolite (estritamente existencialista) - que sustentavam a segunda hipótese - e Vigier e Garaudy (marxistas oriundos das ciências naturais) - que sustentavam a primeira hipótese - travam interessantíssimo debate com argumentações que merecem reflexão à luz dos atuais conhecimentos. Ver: Sartre et al. (1984).
} 
linguagem e as trocas simbólicas, que são determinados e determinantes do próprio metabolismo sociedade-natureza (trabalho). Iasi (2012) organiza esse movimento de constituição do ser social em cinco etapas que não podem ser pensadas isoladamente ou em uma sequência estática e linear: (1) a produção social da existência na interação com a natureza e na produção de instrumentos que permitem a transformação e criação dos meios de vida e a satisfação de necessidades; (2) no próprio movimento de constituição dessas atividades e seus produtos, novas necessidades materiais e simbólicas são criadas e tornam-se tão importantes quanto as necessidades primárias vinculadas à sobrevivência biológica; (3) reprodução da espécie e das relações sociais por meio da família e demais relações coletivas vinculadas à sociabilidade; (4) reprodução de determinados modos de vida, condicionados pelo desenvolvimento das forças produtivas, formas de cooperação, culturas, saberes, e relações sociais estabelecidas; (5) movimento dinâmico das quatro etapas, produzindo a totalidade social. E, de modo sintético, caracteriza a humanidade como:

\begin{abstract}
Os seres que produzem socialmente sua existência e, para isto, alteram a natureza produzindo meios antes não disponíveis, criando novas necessidades sociais que se somam àquelas naturais; que produzem e reproduzem a si mesmos como seres sociais de um determinado modo de vida; que, ao procederem dessa forma coletiva, transformam-se em uma força produtiva combinada que é quantitativamente e qualitativamente distinta da ação individual. (IASI, 2012, p.103).
\end{abstract}

Dessa forma, o humano, enquanto elemento constituinte da natureza, com ela e por meio dela se desenvolve e se (re)afirma, em uma relação dialética de construção e desconstrução em um constante devir, na contraposição com o seu outro: "O homem, portanto, só se desenvolve em relação a esse "outro" de si mesmo, que ele traz dentro de si mesmo: a natureza" (LEFEBVRE, 2011, p.44).

Consequentemente, a natureza só seria redutível a um objeto utilitário se partirmos de uma leitura dualista entre natureza e sociedade e de igual entendimento dual entre trabalho e linguagem. E tal leitura é perfeitamente compatível com as ideologias de uma sociedade produtora de mercadorias, dividida em classes e organizada produtivamente em cima do trabalho alienado e da expropriação material, que reduz o outro a um objeto econômico e mercantil.

O conceito de práxis em Marx não permite separação entre ação instrumental produtora e interação social - por isso, todo trabalho é coletivo. A atividade transformadora não significa reduzir o outro a objeto, mas entender a mútua constituição eu-outro, sujeito-objeto na unidade da natureza ${ }^{12}$. Logo, é correto afirmar que economia e cultura são indissociáveis em Marx, mas como interação dialética repleta de mediações - uma não se esgota na outra e nem expressa diretamente a outra. Para o pensamento crítico, lutar por justiça social e superação das formas de dominação de classe representa garantir a livre realização das potencialidades individuais, ou seja, a construção cultural diversa e não alienada (IASI, 2011).

12 É comum neste tipo de questionamento confundir prioridade ontológica, manifesta no trabalho, enquanto ação metabólica na natureza e transformadora da natureza para garantia da sobrevivência biológica e social da espécie, com hierarquia entre trabalho, linguagem e sociabilidade. $\mathrm{O}$ entendimento dual leva a reduzir o trabalho à dimensão técnico-instrumental, estabelecendo uma hierarquia de importância entre o instrumental e o ético-político e comunicacional que não cabe em Marx. Trabalho é sempre e ontologicamente trabalho coletivo, portanto, trabalho-linguagem-sociabilidade formam, pela práxis, uma unidade dialética em Marx (ANTUNES, 1999, 2005; RANIERI, 2011). 
Por fim, duas passagens ajudam a entender a profundidade da dialética sociedade-natureza no materialismo histórico-dialético, particularmente em Marx.

[...] assim como a sociedade mesma produz o homem enquanto homem, assim ela é produzida por meio dele. A atividade (Tätigkeit) e a fruição, assim como o seu conteúdo, são também os modos de existência segundo a atividade social e a fruição social. A essência humana da natureza está, em primeiro lugar, para o homem social; pois é primeiro aqui que ela existe para ele na condição de elo com o homem, na condição de existência sua para o outro e do outro para ele; é primeiro aqui que ela existe como fundamento da sua própria existência humana, assim como também na condição de elemento vital da efetividade humana. É primeiro aqui que a sua existência natural se lhe tornou a sua existência humana e a natureza [se tornou] para ele o homem. Portanto, a sociedade é a unidade essencial completada (vollendete) do homem com a natureza, a verdadeira ressurreição da natureza, o naturalismo realizado do homem e o humanismo da natureza levado a efeito (MARX, 2004, p.106-107).

O homem é imediatamente ser natural. Como ser natural, e como ser natural vivo, está, por um lado, munido de forças naturais, de forças vitais, é um ser natural ativo; estas forças existem nele como possibilidades e capacidades (Anlagen und Fähigkeiten), como pulsões; por outro, enquanto ser natural, corpóreo, sensível, objetivo, ele é um ser que sofre, dependente e limitado, assim como o animal e a planta, isto é, os objetos de suas pulsões existem fora dele, como objetos independentes dele. Mas esses objetos são objetos de seu carecimento (Bedürfnis), objetos essenciais, indispensáveis para a atuação e confirmação de suas forças essenciais. [...] A fome é uma carência natural; ela necessita, por conseguinte, de uma natureza fora de si, de um objeto fora de si, para se satisfazer, para se saciar. A fome é a carência confessada do meu corpo por um objeto existente (seienden) fora dele, indispensável à sua integração e externação essencial. O sol é o objeto da planta, um objeto para ela imprescindível, confirmador de sua vida, assim como a planta é objeto do sol, enquanto externação da força evocadora de vida do sol, da força essencial objetiva do sol.

Um ser que não tenha sua natureza fora de si não é nenhum ser natural, não toma parte na essência da natureza. Um ser que não tenha nenhum objeto fora de si não é nenhum ser objetivo. Um ser que não seja ele mesmo objeto para um terceiro ser não tem nenhum ser para seu objeto, isto é, não se comporta objetivamente, seu ser não é nenhum [ser] objetivo.

Um ser não-objetivo é um não-ser.[...]

Mas o homem não é apenas ser natural, mas ser natural humano, isto é, ser existente para si mesmo (für sich selbst seiendes Wesen), por isso, ser genérico, que, enquanto tal, tem de atuar e confirmar-se tanto em seu ser quanto em seu saber. Conseqüentemente, nem os objetos humanos são os objetos naturais assim como estes se oferecem imediatamente, nem o sentido humano, tal como é imediata e objetivamente, é sensibilidade humana, objetividade humana. A natureza não está, nem objetiva nem subjetivamente, imediatamente disponível ao ser humano de modo adequado (MARX, 2004, p.127-128).

\section{Breves apontamentos complementares}

Dentro do que foi falado no EPEA, dois aspectos conceituais são pertinentes de serem introduzidos para o cumprimento do objetivo do artigo, considerando o que é de interesse mais direto nas reflexões em educação ambiental. 
A acusação mais comum feita a Marx é a de que ele compartilhava de uma visão determinista da história. O que significa dizer que ele compreendia o futuro da sociedade como um a priori estabelecido em que a ação dos agentes sociais já está previamente definida por razões objetivas independentes das vontades e capacidade dos sujeitos para controlar os processos sociais instituintes.

Deste posicionamento, surgem duas colocações não excludentes. Esse determinismo se fundaria em uma filosofia da história, tal como em Hegel, em que se atribui a ela um sentido e finalidade teleológica, ou em uma teoria da história, pautada em um método que evidencia suas leis causais invariáveis. Isso geraria, consequentemente, um economicismo (por ser a economia o fundamento objetivo da sociedade que determina linearmente o restante) e uma visão messiânica, em que o capitalismo é algo ruim e que o comunismo é a salvação.

Marx era um materialista histórico-dialético e, portanto, não acreditava em salvação ou em julgamentos de valor em relação à sociedade. O capitalismo não é bom ou mal, mas uma sociedade historicamente produzida, com relações determinantes que geram efeitos inerentes à sua dinâmica, como toda sociedade. Seus efeitos, alguns dos quais aqui comentados, possuem consequências sociais e ambientais que são insustentáveis. Superar o capitalismo é uma possibilidade histórica e não algo inevitável, e o que vem depois, se acontecer, não é a perfeição, mas outra sociedade que superará o que é intrínseco ao capitalismo, contudo terá suas próprias contradições que, hoje, desconhecemos (FAUSTO, 2002).

Em concordância com Guimarães (1998, p.37), as formulações de Marx se pautam, primordialmente, em concepções praxiológicas da história, posto que estas:

[...] compreendem o curso da história como definido, de um modo sempre específico e variado, pela vontade organizada dos atores coletivos. Estas vontades coletivas, enraizadas em conflitos gerados no próprio processo de reprodução material destas sociedades e sempre mediados por complexos político-culturais historicamente configurados, são condicionadas na sua formação, na sua autonomia e na sua eficácia histórica. Críticas ao determinismo, mas também ao indeterminismo histórico, as concepções praxiológicas autorizam previsões históricas condicionadas, concretas e formuladas em termos de campos de possibilidade ou tendencialidades.

A história, em Marx, não se refere a uma sucessão de fatos e ideias no tempo, mas ao modo concreto como produzimos nossa existência social sob certas condições. Isso significa procurar entender a indissociação entre o sujeito, a ação e o produto desta e as características tendenciais que a sociedade assume nesse movimento (LUKÁCS, 2013).

\footnotetext{
A história não faz nada, ela não "possui enorme riqueza", ela "não trava combates"! Ao contrário, é o homem, o homem real e vivo que faz tudo isso, possui tudo isso e conduz todos esses combates; não é, estejais certos disso, a "história" que se serve do homem como meio para realizar - como se ela fosse uma pessoa à parte - seus próprios fins; ela é apenas a atividade do homem que busca seus próprios fins. (MARX; ENGELS, 2001, p.93).
}

Consequentemente, não faz muito sentido afirmar que há em Marx um determinismo econômico ao longo de toda a história, unificando-a. Uma universalização mecânica pela economia só é possível pela negação das múltiplas determinações, das contradições e das mediações sociais. O que há é o entendimento dos processos 
econômicos como ontologicamente determinantes da vida social, posto que aí se definem as formas de produção, relações de propriedade em torno daquilo que é gerado para garantir a sobrevivência da espécie e os meios instituídos para a sociedade assegurar sua reprodução e existência. Ora, isto não significa desconsiderar as demais dimensões, mas exatamente relacioná-las dialeticamente à economia na totalidade social. Se fosse diferente, não haveria como entender, por exemplo, suas análises do mundo antigo e da Idade Média (MARX, 1991), quando fala explicitamente de modos de dominação para explicar seus funcionamentos (CHAUÍ, 2006a).

\begin{abstract}
A totalidade social na teoria marxista é um complexo geral estruturado e historicamente determinado. Existe nas e através das mediações e transições múltiplas pelas quais suas partes específicas ou complexas - isto é, as totalidades parciais - estão relacionadas entre si, numa série de interrelações e determinações recíprocas que variam constantemente e se modificam. A significação e os limites de uma ação, medida, realização, lei etc. não podem, portanto, ser avaliados, exceto em relação à apreensão dialética da estrutura da totalidade. Isso, por sua vez, implica necessariamente a compreensão dialética das mediações concretas múltiplas que constituem a estrutura de determinada totalidade social (BOTTOMORE, 2001, p.381).
\end{abstract}

Passando ao segundo aspecto, a afirmação comum de que Marx era adepto de certo espírito prometéico, próprio da modernidade, faz sentido quando pensado em termos da confiança na capacidade humana de definir seus destinos, portanto, na negação a todas as concepções que colocam a finalidade da existência humana fora da práxis. Naquele momento histórico, o entusiasmo com o sucesso do avanço tecnológico e com a superação de visões que colocavam o ser humano numa condição passiva diante dos desígnios divinos era evidente não somente em Marx. Ou seja, as condições apresentadas sinalizavam para a aceitação de um otimismo que, hoje, certamente não se sustenta.

Além das sempre utilizadas referências a colocações de Engels ${ }^{13}$, afirmando que a natureza se vingaria das ações humanas destrutivas (LÖWY, 2005), esta crença de que Marx era adepto incondicional do progresso começa a ser efetivamente questionável, no entanto, ao lermos a crítica aguda feita ao anarquista Proudhon, em Miséria da Filosofia (MARX, 2001).

No tópico o excedente do trabalho, Marx dirige sua reflexões para a demolição do otimismo de Proudhon quanto à capacidade de desenvolvimento tecnológico ser equivalente à garantia e ampliação da felicidade para as pessoas, como se fosse possível desvincular tal avanço do modo de produção e das relações de propriedade e seus efeitos sobre a sobrevivência do trabalhador e o equilíbrio metabólico da natureza. Já nessa obra, alerta para a possibilidade de o desenvolvimento tecnológico ser fator de

\footnotetext{
${ }^{13}$ Há pelo menos uma passagem célebre escrita em 1876, que diz: "Contudo, não nos deixemos dominar pelo entusiasmo em face de nossas vitórias sobre a natureza. É verdade que as primeiras conseqüências dessas vitórias são as previstas por nós, mas em segundo e em terceiro lugar aparecem conseqüências muito diversas, totalmente imprevistas e que, com freqüência anulam as primeiras [...] Assim, a cada passo, os fatos recordam que nosso domínio sobre a natureza não se parece em nada com o domínio de um conquistador sobre o povo conquistado, que não é o domínio de alguém situado fora da natureza, que nós, por nossas carne, nosso sangue e nosso cérebro, pertencemos à natureza, encontramo-nos em seu seio.......] E quanto mais isso seja uma realidade, mais os homens sentirão e compreenderão sua unidade com a natureza, e mais inconcebível será essa idéia absurda e antinatural de antítese entre espírito e matéria, o homem e a natureza, a alma e o corpo..." (ENGELS, 2004, p. 30).
} 
aumento da submissão do trabalho ao capital, com graves consequências que negariam o otimismo no progresso como sinônimo de inexorável avanço rumo ao paraíso terreno.

O conceito de progresso expressa, a rigor, segundo Chauí (2006, p.78), a ideologia burguesa de explicar a história por meio de um processo evolutivo rumo ao melhor e ao superior.

\begin{abstract}
O historiador-ideólogo constrói a idéia de progresso histórico concebendo-o como a realização, no tempo, de algo que já existia antes de forma embrionária e que se desenvolve até alcançar seu ponto final necessário. Visto que a finalidade do processo já está dada (isto é, já se sabe de antemão qual vai ser o futuro), e visto que o progresso é uma "lei" da história, esta irá alcançar necessariamente o fim conhecido. Com isso, os homens tornam-se instrumentos ou meios para a "história" realizar seus fins próprios, e são justificadas todas as ações que se realizam "em nome do progresso".
\end{abstract}

Em cima do que foi dito até aqui, a lógica mecanicista e linear inerente a esse conceito não é compatível com as categorias dialéticas que indicam para uma noção de sociedade e de natureza construída sobre a noção de equilíbrio dinâmico/desequilíbrio estrutural (BENSAÏD, 1999). A obra de Marx implica em tempos múltiplos, decorrentes das complexas interrelações entre processos econômicos (produção, circulação, distribuição, consumo, reprodução e transformação), e cíclicos (em sentido sistêmico), definidos a partir das condições objetivas (relações e modos de produção, incluindo a tecnologia e as formas de propriedade) e da ação dos agentes sociais (configuração das relações sociais e da luta de classes).

\title{
4. Considerações finais
}

Em um momento em que as questões ambientais ocupam espaços proeminentes nos discursos e práticas, entendo que a inovação e a inquietação própria do ambientalismo, e particularmente da educação ambiental, não são garantia de que sejam portadoras de processos transformadores na cultura e na economia, em síntese, da sociedade e do padrão civilizatório mundializado. Para isso, é preciso que o questionamento e a vontade de criar algo novo se relacionem à crítica radical às relações sociais concretas e ao sociometabolismo do capital. Tarefa para a qual a tradição marxista e a adoção do materialismo histórico-dialético possuem indiscutíveis contribuições.

$E^{E}$ igualmente decisivo que a tradição crítica se repense, rompendo com os grilhões de todas as formas dogmáticas de pensamento que enrijeceram as possibilidades transformadoras presentes no pensamento marxista. Mais do que isso, é fundamental que os que com esta tradição se identificam, reconheçam a prioridade constitutiva da natureza e conheçam as dinâmicas sociais e ecossistêmicas no metabolismo sociedade-natureza.

São desafios que, diante da grave crise societária e ecológica vivenciada, exigem compromisso político, prático e cotidiano, com a transformação do conjunto das relações sociais e demandam a permanente inquietação intelectual e não aceitação dos processos de destruição planetária. 


\section{Referências}

ALTVATER, E. O fim do capitalismo como o conhecemos. Rio de Janeiro: Civilização Brasileira, 2010.

ALTVATER, E. Existe um marxismo ecológico? In: BORON, A. A.; AMADEO, J.; GONZÁLEZ, S. (Orgs.). La teoría marxista hoy: problemas y perspectivas. Buenos Aires: CLACSO, 2006.

ANTUNES, R. Os sentidos do trabalho: ensaios sobre a afirmação e a negação do trabalho. São Paulo: Boitempo, 1999.

ANTUNES, R. Adeus ao trabalho? Ensaio sobre as metamorfoses e a centralidade do mundo do trabalho. $10^{\mathrm{a}}$ ed. São Paulo: Cortez, 2005.

BENOIT, H. Da dialética da natureza a derradeira estratégia política de Engels. In: BOITO JR., A. et al. (Orgs.). A obra teórica de Marx: atualidade, problemas e interpretações. São Paulo: Xamã, 2000.

BENSAÏD, D. Marx, o intempestivo: grandezas e misérias de uma aventura crítica. Rio de Janeiro: Civilização Brasileira, 1999.

BORNHEIM, G. A. Dialética: teoria, práxis - ensaio para uma crítica da fundamentação ontológica da dialética. São Paulo: Edusp, 1977.

BORON, A. Clase inaugural: por el necesario (y demorado) retorno al marxismo. In: BORON, A. A.; AMADEO, J.; GONZÁLEZ, S. La teoría marxista hoy: problemas y perspectivas. Buenos Aires: CLACSO, 2006.

BOTTOMORE, T. (Ed.). Dicionário do pensamento marxista. Rio de Janeiro: Jorge Zahar Editor, 2001.

CASANOVA, P. G. Sociología de la explotación. Buenos Aires: CLACSO, 2006.

CASANOVA, P. G. Las nuevas ciencias y las humanidades: de la academia a la política. Barcelona: Anthropos Editorial; México: Instituto de Investigaciones Sociales; Madrid: Editorial Complutense, 2004.

CHASIN, J. Marx: estatuto ontológico e resolução metodológica. São Paulo: Boitempo, 2009.

CHAUÍ, M. O que é ideologia. $8^{\mathrm{a}}$ reimpressão, $2^{\mathrm{a}}$ ed. São Paulo: Brasiliense, 2006.

CHAUÍ, M. La historia en el pensamiento de Marx. In: BORON, A. A.; AMADEO, J.; GONZÁLEZ, S. (Orgs.). La teoría marxista hoy: problemas y perspectivas. Buenos Aires: CLACSO, 2006a.

CHESNAIS, F. A mundialização do capital. São Paulo: Xamã, 1996.

DEBORD, G. A Sociedade do espetáculo. São Paulo: Contraponto, 1997.

DUARTE, R. A. de P. Marx e a natureza em O Capital. $2^{a}$ ed. São Paulo: Loyola, 1995. 
DUSSEL, E. A produção teórica de Marx: um comentário aos Grundrisse. São Paulo: Expressão Popular, 2012.

EAGLETON, T. Marx estava certo. Rio de Janeiro: Nova Fronteira, 2012.

EAGLETON, T. As ilusões do pós-modernismo. Rio de Janeiro: Jorge Zahar, 1998.

ENGELS, F. Sobre o papel do trabalho na transformação do macaco em homem. In: ANTUNES, R. (Org.) A dialética do trabalho. São Paulo: Expressão Popular, 2004.

FAUSTO, R. Marx: lógica e política - investigações para uma reconstrução do sentido da dialética. Tomo III. São Paulo: Editora 34, 2002.

FOSTER, J. B. A ecologia de Marx: materialismo e natureza. Rio de Janeiro: Civilização Brasileira, 2005.

FOSTER, J. B. Ecology against capitalism. London: Monthly Review Press, 2002.

FOSTER, J. B. Marx e o meio ambiente. In: WOOD, E. M.; FOSTER, J. B. Em defesa da história: marxismo e pós-modernismo. Rio de Janeiro: Jorge Zahar, 1999.

GUIMARÃES, J. Democracia e marxismo: crítica à razão liberal. São Paulo: Xamã, 1998.

HARVEY, D. Para entender o Capital. Livro 1. São Paulo: Boitempo, 2013.

HARVEY, D. Os limites do capital. São Paulo: Boitempo, 2013a.

HARVEY, D. O enigma do capital. São Paulo: Boitempo, 2011.

HARVEY, D. Espaços de esperança. São Paulo: Loyola, 2005.

HAUG, F. Hacia una teoría de las relaciones de género. In: BORON, A. A.; AMADEO, J.; GONZÁLEZ, S. (Orgs.). La teoría marxista hoy: problemas y perspectivas. Buenos Aires: CLACSO, 2006.

HORKHEIMER, M. Teoria crítica: uma documentação. São Paulo: Perspectiva, 1990.

IASI, M. L. As metamorfoses da consciência de classe: o PT entre a negação e o consentimento. $2^{a}$ ed. São Paulo: Expressão Popular, 2012.

IASI, M. L. Ensaios sobre consciência e emancipação. $2^{\mathrm{a}}$ ed. São Paulo: Expressão Popular, 2011.

JAMESON, F. Pós-modernismo - a lógica cultural do capitalismo tardio. São Paulo: Ática, 1996.

KOFLER, L. História e dialética: estudos sobre a metodologia da dialética marxista. Rio de Janeiro: EDUFRJ, 2010.

KONDER, L. O que é dialética. $28^{\mathrm{a}}$ ed. São Paulo: Brasiliense, 1997.

KONDER, L. O futuro da filosofia da práxis - o pensamento de Marx no século XXI. $2^{\mathrm{a}}$ ed. Rio de Janeiro: Paz e Terra, 1992. 
KOSIK, K. Dialética do concreto. $5^{\text {a }}$ ed. Rio de Janeiro: Paz e Terra, 1976.

LABICA, G. As “Teses sobre Feuerbach” de Karl Marx. Rio de Janeiro: Jorge Zahar, 1990.

LEFEBVRE, H. Marxismo. Porto Alegre: L\&PM, 2011.

LESSA, S. A materialidade do trabalho e o "trabalho imaterial". Revista Outubro, São Paulo, Outubro n. 8, p.27-46, jan.-jun. 2003.

LOUREIRO, C. F. B. Sustentabilidade e educação: um olhar da ecologia política. São Paulo: Cortez, 2012.

LOUREIRO, C. F. B. Problematizando conceitos: contribuição à práxis em educação ambiental. In:

.; LAYRARGUES, P. P.; CASTRO, R. S. de. (Orgs.). Pensamento complexo, dialética e educação ambiental. $2^{\mathrm{a}}$ ed. São Paulo: Cortez, 2011.

LÖWY, M. O marxismo na América Latina: uma antologia de 1909 aos dias atuais. $2^{\text {a }}$ ed. São Paulo: Fundação Perseu Abramo, 2006.

LÖWY, M. Ecologia e socialismo. São Paulo: Cortez, 2005.

LUKÁCS, G. Para uma ontologia do ser social. Vol. II. São Paulo: Boitempo, 2013.

LUKÁCS, G. Para uma ontologia do ser social. Vol. I. São Paulo: Boitempo, 2012.

LUKÁCS, G. Prolegômenos: para uma ontologia do ser social. São Paulo: Boitempo, 2010.

MARIÁTEGUI, J. C. Por um socialismo indo-americano. Rio de Janeiro: EDUFRJ, 2005.

MARX, K. O capital: crítica da economia política. Livro I - o processo de produção do Capital. Volume 1. 23ª ed. Rio de Janeiro: Civilização Brasileira, 2006.

MARX, K. Manuscritos econômico-filosóficos. São Paulo: Boitempo, 2004.

MARX, K. Gotha: comentários à margem do Programa Operário Alemão - 1875. In:

ENGELS, F. (Orgs.). Manifesto do partido comunista (1848). Porto Alegre: L\&PM, 2002.

MARX, K. Miséria da filosofia: resposta à filosofia da miséria de Proudhon. São Paulo: Centauro, 2001.

MARX, K. Formações econômicas pré-capitalistas. $6^{a}$ ed. Rio de Janeiro: Paz e Terra, 1991.

MARX, K.; ENGELS, F. A ideologia alemã. 3ª ed. São Paulo: Martins Fontes, 2002.

MARX, K.; ENGELS, F. A sagrada família. São Paulo: Centauro, 2001.

MÉSZÁROS, I. O conceito de dialética em Lukács. São Paulo: Boitempo, 2013.

MÉSZÁROS, I. A teoria da alienação em Marx. São Paulo: Boitempo, 2006.

MÉSZÁROS, I. O poder da ideologia. São Paulo: Boitempo, 2004. 
MÉSZÁROS, I. Para além do capital. São Paulo: Boitempo, 2002.

MOTA, R. O pseudo-materialismo de Karl Marx. Monfort Associação Cultural. Disponível em: $<$ http://www.montfort.org.br/old/index.php?secao=veritas\&subsecao=historia\&artigo=pseudo_ mat_marx\&lang=bra>. Acesso em: 24 abr. 2014.

NETTO, J.P. (Org.) O leitor de Marx. Rio de Janeiro: Civilização Brasileira, 2012.

O'CONNOR, J. Desarrollo desigual y combinado y crisis ecológica. Ambiente e Sociedade, Campinas, v.6, n.2, p.9-23, jul./dez. 2003.

PORTO-GONÇALVES, C. W. Os (des)caminhos do meio ambiente. São Paulo: Contexto, 1989.

RANIERI, J. Trabalho e dialética: Hegel, Marx e a teoria social do devir. São Paulo: Boitempo, 2011.

SALLUM JR., B. Classes, cultura e ação coletiva. Lua Nova, São Paulo, n. 65, p.11-42, 2005.

SAMPAIO, B. A.; FREDERICO, C. Dialética e materialismo: Marx entre Hegel e Feuerbach. Rio de Janeiro: EDUFRJ, 2006.

SARTRE, J. P. et al. Marxismo e existencialismo (controvérsias sobre a dialética). $2^{\mathrm{a}}$ ed. Rio de Janeiro: Tempo Brasileiro, 1984.

SAVIANI, D. Perspectiva marxiana do problema subjetividade-intersubjetividade. In: DUARTE, N. (Org.) Crítica ao fetichismo da individualidade. Campinas: Autores Associados, 2004.

STORLOKEN, T. Mulheres em tempos sombrios: Rosa Luxemburg e Hannah Arendt. Crítica Marxista, Campinas, n. 23, p.111-128, 2006.

TERTULIAN, N. Adorno-Lukács: polêmicas e mal-entendidos. À margem esquerda, São Paulo, n.9, p.73-97, 2007.

VÁZQUEZ, A. S. Filosofia da práxis. 2ª ed. São Paulo: Expressão Popular, 2011.

WALLERSTEIN, I. Capitalismo histórico e civilização capitalista. Rio de Janeiro: Contraponto, 2001.

ZIEGLER, J. Destruição em massa: geopolítica da fome. São Paulo: Cortez, 2013.

Artigo submetido em 26/11/2013

Artigo aprovado em 20/02/2014 